Old Dominion University

ODU Digital Commons

CCPO Publications

Center for Coastal Physical Oceanography

2011

\title{
Improving Simulations of the Upper Ocean by Inclusion of Surface Waves in the Mellor-Yamada Turbulence Scheme
}

Chuan Jiang Huang

Fangli Qiao

Zhenya Song

Tal Ezer

Old Dominion University, tezer@odu.edu

Follow this and additional works at: https://digitalcommons.odu.edu/ccpo_pubs

Part of the Atmospheric Sciences Commons, Climate Commons, and the Oceanography Commons

\section{Repository Citation}

Huang, Chuan Jiang; Qiao, Fangli; Song, Zhenya; and Ezer, Tal, "Improving Simulations of the Upper Ocean by Inclusion of Surface Waves in the Mellor-Yamada Turbulence Scheme" (2011). CCPO Publications. 134.

https://digitalcommons.odu.edu/ccpo_pubs/134

\section{Original Publication Citation}

Huang, C.J., Qiao, F.L., Song, Z.Y., \& Ezer, T. (2011). Improving simulations of the upper ocean by inclusion of surface waves in the Mellor-Yamada turbulence scheme. Journal of Geophysical Research: Oceans, 116(C01007), 1-13. doi: 10.1029/2010jc006320

This Article is brought to you for free and open access by the Center for Coastal Physical Oceanography at ODU Digital Commons. It has been accepted for inclusion in CCPO Publications by an authorized administrator of ODU Digital Commons. For more information, please contact digitalcommons@odu.edu. 


\title{
Improving simulations of the upper ocean by inclusion of surface waves in the Mellor-Yamada turbulence scheme
}

\author{
Chuan Jiang Huang, ${ }^{1}$ Fangli Qiao, ${ }^{1}$ Zhenya Song, ${ }^{1}$ and Tal Ezer ${ }^{2}$ \\ Received 5 April 2010; revised 11 October 2010; accepted 8 November 2010; published 19 January 2011.
}

[1] The Mellor-Yamada turbulence closure scheme, used in many ocean circulation models, is often blamed for overly high simulated surface temperature and overly low simulated subsurface temperature in summer due to insufficient vertical mixing. Surface waves can enhance turbulence kinetic energy and mixing of the upper ocean via wave breaking and nonbreaking-wave-turbulence interaction. The influences of wave breaking and wave-turbulence interaction on the Mellor-Yamada scheme and upper ocean thermal structure are examined and compared with each other using one-dimensional and threedimensional ocean circulation models. Model results show that the wave-turbulence interaction can effectively amend the problem of insufficient mixing in the classic MellorYamada scheme. The behaviors of the Mellor-Yamada scheme, as well as the simulated upper ocean thermal structure, are significantly improved by adding a turbulence kinetic energy production term associated with wave-turbulence interaction. In contrast, mixing associated with wave breaking alone seems insufficient to improve significantly the simulations as its effect is limited to the very near-surface layers. Therefore, the effects of wave-turbulence interaction on the upper ocean are much more important than those of wave breaking.

Citation: Huang, C. J., F. Qiao, Z. Song, and T. Ezer (2011), Improving simulations of the upper ocean by inclusion of surface waves in the Mellor-Yamada turbulence scheme, J. Geophys. Res., 116, C01007, doi:10.1029/2010JC006320.

\section{Introduction}

[2] Vertical mixing plays a significant role in the temperature structure and circulation of the world's oceans. A proper parameterization of vertical mixing is essential for numerical ocean circulation models. Various vertical mixing schemes have been developed for different models; of those schemes, the turbulence closure scheme of Mellor and Yamada [1982, M-Y hereafter] has been used extensively in atmosphere and ocean numerical models.

[3] Although models with the M-Y scheme can successfully reproduce many general features of the ocean, it does have some deficiencies, so various remedies have been proposed over the years to improve the scheme [Kantha and Clayson, 1994; Ezer, 2000; Mellor, 2001]. In particular, insufficient mixing in the upper ocean during summer is a common problem of ocean circulation models, and there are no exceptions for models using $\mathrm{M}-\mathrm{Y}$ scheme. The result of insufficient mixing is too high sea surface temperature (SST) [Martin, 1985] and too low subsurface temperature [Ezer, 2000]. In fact, the M-Y scheme was developed for stratified boundary layers near rigid surfaces, in which the principal balance in the turbulence kinetic energy (TKE)

\footnotetext{
${ }^{1}$ Key Laboratory of Marine Science and Numerical Modeling, First Institute of Oceanography, State Oceanic Administration, Qingdao, China.

${ }^{2}$ Center for Coastal Physical Oceanography, Old Dominion University, Norfolk, Virginia, USA.

Copyright 2011 by the American Geophysical Union. 0148-0227/11/2010JC006320
}

equation is among the local shear production, buoyant production, and dissipation [Mellor and Yamada, 1982]. This assumption may be appropriate for atmosphere models, but not for ocean models if the presence of surface waves in the ocean is considered.

[4] Surface waves at the air-sea interface play an important role in the TKE budget for the upper ocean. Wind energy input to surface waves is estimated as 60 70 TW [Wang and Huang, 2004; Rascle et al., 2008], which is much greater than the mechanical energy from all other sources in the ocean [Ferrari and Wunsch, 2009]. To simulate the upper ocean accurately, it is necessary to incorporate the effects of surface waves into the M-Y scheme, in the hope to improve the performance of ocean models.

[5] Most of the wave energy is locally dissipated through wave breaking [Donelan, 1998], which greatly enhances the TKE near the sea surface [Agrawal et al., 1992; Drennan et al., 1996]. Wave-breaking effects have been added to the original M-Y scheme by Mellor and Blumberg [2004] through modifying the surface boundary condition of the TKE equation. In the studies by Mellor and Blumberg [2004] and Sun et al. [2005], wave breaking improved somewhat the simulations of SST and mixed layer depth (MLD) when compared with those by the original M-Y scheme, while D'Alessio et al. [1998], Burchard [2001], and Zhang et al. [2007] argued that wave breaking cannot affect the upper ocean temperature because the strong turbulence induced by wave breaking is mainly confined within the near-surface zone with the depth scale of wave 
height [Rapp and Melville, 1990; Craig and Banner, 1994; Soloviev and Lukas, 2003]. Thus, over the years, how much effect the wave breaking really has on ocean mixing remains a controversial issue.

[6] Besides wave breaking, nonbreaking surface waves can directly transfer energy from the surface wave to the turbulence because the surface waves are not truly irrotational or potential before breaking. This has been confirmed by theoretical analyses [Phillips, 1961; Kitaigorodskii et al., 1983; Ardhuin and Jenkins, 2006], laboratory experiments [Cheung and Street, 1988; Teixeira and Belcher, 2002; Babanin and Haus, 2009; Dai et al., 2010], and field observations [Anis and Moum, 1995; Gemmrich and Farmer, 2004; Veron et al., 2009]. The energy transfer associated with nonbreaking surface waves is usually attributed to wave-turbulence interaction (or wave-current-turbulence interaction). Qiao et al. [2004, 2010] derived a parameterization scheme of nonbreaking wave-induced vertical mixing from the wave number spectrum, depicting the coupling of ocean models with wave models. Adopting this scheme to coastal and global circulation models [e.g., Qiao et al., 2004; Lin et al., 2006], as well as climate models [Song et al., 2007; Huang et al., 2008] resulted in significant improvements in the simulations of the upper ocean temperature structure. Other processes such as Langmuir cells have also been sought to be incorporated into ocean models. The results show that these processes can affect the SST and the MLD [D'Alessio et al., 1998; Kantha and Clayson, 2004].

[7] Recently, regarding the wave-turbulence interaction as an additional source of TKE, Huang and Qiao [2010] introduced a parameterization scheme of wave-turbulence interaction and incorporated the scheme to a one-dimensional model with the M-Y scheme. The modified model shows significant improvements in simulating turbulence characteristics compared with the original model. This article further analyzes the influences of wave-turbulence interaction on the M-Y scheme and the upper ocean simulation, along with comparison of the wave-breaking effect. Section 2 will discuss model modifications related to wave breaking and wave-turbulence interaction. Effects of wave breaking and wave-turbulence interaction on one-dimensional models are compared using idealized forcing experiments in section 3 and ocean station data in section 4 . In section 5 , the wave-turbulence interaction effects are further discussed by a three-dimensional model. Section 6 gives conclusions of this study.

\section{Inclusion of Wave-Turbulence Interaction and Wave Breaking}

[8] In the classic level 2.5 version of the M-Y turbulence closure model [Mellor and Yamada, 1982], the vertical viscosity $K_{m}$ and the diffusivity $K_{h}$ are calculated from

$$
\begin{aligned}
& K_{m}=q l S_{m}, \\
& K_{h}=q l S_{h},
\end{aligned}
$$

where $q^{2} / 2$ is the TKE, $l$ is a turbulence length scale, and $S_{m}$ and $S_{h}$ are stability functions associated with the Richardson number, which is defined as $G_{h}=-l^{2} N^{2} / q^{2}$. Two prognostic equations are solved for $q^{2}$ and $l$ as follows:

$$
\begin{gathered}
\frac{D}{D t}\left(\frac{q^{2}}{2}\right)-\frac{\partial}{\partial z}\left[K_{q} \frac{\partial}{\partial z}\left(\frac{q^{2}}{2}\right)\right]=P_{S}+P_{b}-\varepsilon, \\
\frac{D q^{2} l}{D t}-\frac{\partial}{\partial z}\left[K_{q} \frac{\partial q^{2} l}{\partial z}\right]=E_{1} l\left[P_{S}+E_{3} P_{b}\right]-l \varepsilon \tilde{W},
\end{gathered}
$$

where $K_{q}$ is the vertical turbulence diffusivity, $P_{b}$ is the buoyant production, $\tilde{W}$ is a wall proximity function, $E_{1}$ and $E_{3}$ are nondimensional constants,

$$
P_{S}=K_{m}\left[\left(\frac{\partial u}{\partial z}\right)^{2}+\left(\frac{\partial v}{\partial z}\right)^{2}\right]
$$

is the shear production of TKE,

$$
\varepsilon=\frac{q^{3}}{B_{1} l}
$$

is the TKE dissipation rate, $u$ and $v$ are horizontal velocity components, and $B_{1}(=16.6)$ is an empirical constant.

[9] In the classic M-Y model, the surface boundary conditions for these two prognostic equations are

$$
\begin{gathered}
q^{2}(0)=B_{1}^{2 / 3} u_{*}^{2}, \\
q^{2} l(0)=0 .
\end{gathered}
$$

[10] The wave-breaking effect is usually incorporated into the M-Y scheme by modifying equations (5a) and (5b). Mellor and Blumberg [2004] incorporated the wave-breaking parameterization obtained by Craig and Banner [1994] into the M-Y scheme, in which the boundary conditions were changed to

$$
\begin{aligned}
& q^{2}(0)=\left(15.8 \alpha_{C B}\right)^{2 / 3} u_{*}^{2}, \\
& l(0)=\kappa z_{w}=\kappa \beta_{C B} u_{*}^{2} / g,
\end{aligned}
$$

where $\kappa=0.41$ is the von Karman constant, $z_{w}$ is a surface roughness length, $\alpha_{C B}(=100)$, and $\beta_{C B}\left(=2 \times 10^{5}\right)$ are empirical constants; $u_{*}=\sqrt{\tau_{0} / \rho}$ is the friction velocity on the sea surface, $\tau_{0}$ is the surface wind stress, and $\rho$ is the density of seawater.

[11] Recently, Huang and Qiao [2010] introduced a parameterization of the TKE dissipation rate induced by wave-turbulence interaction as

$$
\varepsilon_{w}=148 \beta \sqrt{\delta} \frac{u_{s 0} u_{*}^{2}}{L} e^{2 k z},
$$

where $\beta$ is a dimensionless constant that is usually set to 1.0 . $\delta\left(=H_{S} / L\right)$ is the wave steepness, $H_{s}$ is the significant wave height, and $L$ is the wavelength, $u_{s 0}=c(A k)^{2}$ is the magnitude of the Stokes drift at the surface (or at $z=0$ ), $c$ is the wave phase velocity, $A\left(=H_{S} / 2\right)$ is the wave amplitude, $k$ 
Table 1. Model Experiments Conducted ${ }^{\mathrm{a}}$

\begin{tabular}{|c|c|c|c|c|c|c|c|}
\hline \multirow[b]{2}{*}{ Effect } & \multirow[b]{2}{*}{ Wind Deepening } & \multicolumn{3}{|c|}{ Heating } & \multirow[b]{2}{*}{ Cooling } & \multirow[b]{2}{*}{ Papa } & \multirow[b]{2}{*}{ OGCM } \\
\hline & & Normal Wind & Weak Wind & Strong Wind & & & \\
\hline No waves & W1 & H1 & Hal & $\mathrm{Hb} 1$ & $\mathrm{C} 1$ & P1 & G1 \\
\hline Wave breaking & W2 & $\mathrm{H} 2$ & $\mathrm{Ha} 2$ & $\mathrm{Hb} 2$ & $\mathrm{C} 2$ & $\mathrm{P} 2$ & G2 \\
\hline Wave-turbulence interaction & W3 & $\mathrm{H} 3$ & $\mathrm{Ha} 3$ & $\mathrm{Hb} 3$ & $\mathrm{C} 3$ & P3 & G3 \\
\hline
\end{tabular}

${ }^{a}$ Every group of experiments included three cases: the first case is a control experiment, in which effects of surface waves are not included; the second case includes wave-breaking effects as in equation (6a) and (6b); and the third case includes the effect of wave-turbulence interaction as in equation (8).

$(=2 \pi / L)$ is the wave number, and $z$ is the vertical coordinate with zero at the mean sea level and the positive upward.

[12] In this parameterization, the TKE dissipation rate induced by wave-turbulence interaction is a function of $u_{s 0}$ $u_{*}^{2}$ and wave parameters, and it decays with the depth away from the surface in the form of $e^{2 k z}$. As the wave-turbulence interaction transfers energy from wavefields to the turbulence, it is reasonable for the TKE production in the M-Y scheme to include its effect when surface waves are present, i.e.,

$$
P_{S}=K_{m}\left[\left(\frac{\partial u}{\partial z}\right)^{2}+\left(\frac{\partial v}{\partial z}\right)^{2}\right]+\varepsilon_{w}
$$

[13] The influences of wave-turbulence interaction and wave breaking on the M-Y scheme and the upper ocean simulation will be examined in sections 3-5 using the results of numerical experiments. Each group of numerical experiments includes three cases (Table 1): the first case is based on the classic/original M-Y scheme, in which effects of surface waves are not included; the second case includes wave-breaking effects via modifying the surface TKE flux and roughness length as in equations (6a) and (6b); and the third case includes the effects of wave-turbulence interaction as in equation (8).

\section{One-Dimensional Experiments With Idealized Forcing}

[14] This section uses a one-dimensional model to examine the behavior of the M-Y scheme by including wave breaking or wave-turbulence interaction. This model is similar to that used by Mellor and Blumberg [2004]. Following Martin [1985] and D'Alessio et al. [1998], several groups of experiments are carried out with idealized forcing, including wind deepening (experiments W1-W3), heating (experiments $\mathrm{H} 1-\mathrm{H} 3$ ), and cooling (experiments $\mathrm{C} 1-\mathrm{C} 3$ ). In those experiments, the water depth is set to $200 \mathrm{~m}$ with a model vertical resolution of $2 \mathrm{~m}$. The time step is $120 \mathrm{~s}$, and the latitude is taken to be $29.91^{\circ} \mathrm{N}$, where the inertial period is $24 \mathrm{~h}$.

[15] The significant wave height $H_{s}$, the period $T_{s}$, and the surface wind stress $\tau_{0}$ are used for calculating the dissipation rate induced by wave-turbulence interaction via equation (7). Following Kantha and Clayson [2004], the following are set: $H_{s}=1.6 \mathrm{~m}$ and $T_{s}=6.2 \mathrm{~s}$, which approximately corresponds to a fully developed sea state under the wind stress of $0.1 \mathrm{~N} \mathrm{~m}^{-2}$.

\subsection{Wind Deepening}

[16] For this group of numerical experiments, the initial conditions are as follows. The SST is equal to $24^{\circ} \mathrm{C}$ and thermal stratification is a uniform $0.05^{\circ} \mathrm{C} \mathrm{m}^{-1}$; the salinity is constant of $35 \mathrm{psu}$, and the velocity is zero. The surface wind stress is set to be $0.1 \mathrm{~N} \mathrm{~m}^{-2}$, and the surface heat flux and the freshwater flux are zero.

[17] Figure 1 shows the evolution of the SST in the experiments of W1 (control run), W2 (wave breaking), and W3 (wave-turbulence interaction). One can see that the SST in experiment $\mathrm{W} 2$ is almost the same as that in experiment $\mathrm{W} 1$, while it decreases significantly in experiment W3. The changes in SST are attributed to those in turbulence characteristics in the experiments. In experiment W2, the enhanced turbulence velocity $q$ by wave breaking is limited to the first few meters near the surface (Figure 2c). In the $\mathrm{M}-\mathrm{Y}$ scheme, the dissipation rate $\varepsilon$ and the vertical diffusivity $K_{h}$ are closely associated with $q$; then, the high values of the simulated $\varepsilon$ and $K_{h}$ are also confined to the near-surface zone (Figures $2 \mathrm{~d}$ and 2f). Thus, if the MLD is deeper than this wave-breaking affected zone, wave breaking has little effect on either mixed layer deepening or the upper thermal structure (Figure 2a).

[18] In experiment W3, however, the enhanced $q$ by wave-turbulence interaction extends into much greater depth compared to that in experiment W2 (Figure 2c), although $l$ shows little change (Figure 2b). This change in $q$ enhances the simulated $\varepsilon$ significantly (Figure $2 \mathrm{~d}$ ). At the same time, they can cause an increase of the stability factor $S_{h}$ via changing the Richardson number $G_{h}$ (Figure 2e). In the M-Y scheme, the vertical diffusivity $K_{h}$ is proportional to $q, l$, and $S_{h}$. Thus, the simulated $K_{h}$ in experiment W3 is much larger than that in experiment W1 (Figure 2f), which

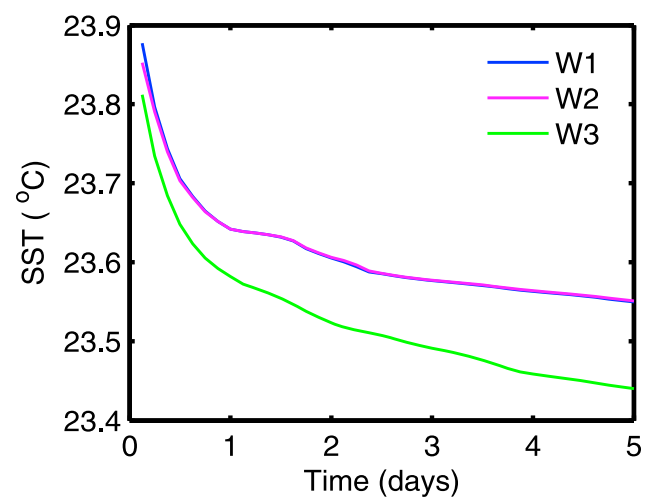

Figure 1. Simulated SST for experiments W1-W3. 
(a) $\mathrm{T}\left({ }^{\circ} \mathrm{C}\right)$

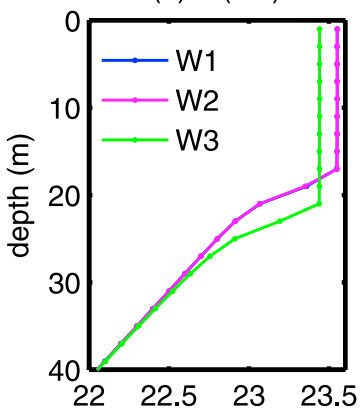

(b) $\mid(\mathrm{m})$

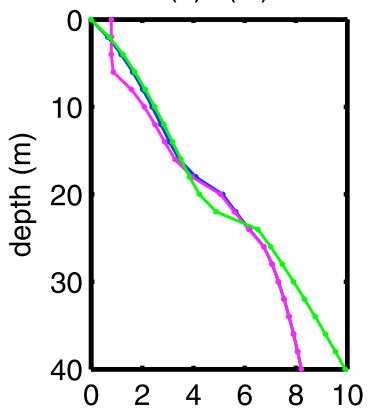

(c) $q\left(\mathrm{~m} \mathrm{~s}^{-1}\right)$

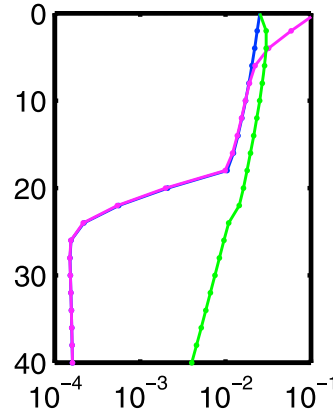

(d) $\varepsilon\left(\mathrm{m}^{2} \mathrm{~s}^{-3}\right)$

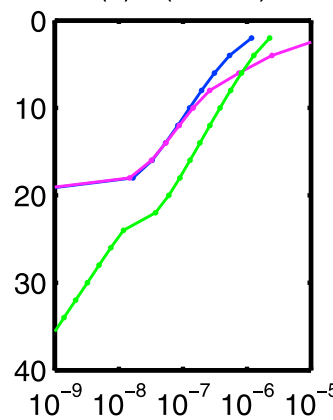

(e) $S_{h}$

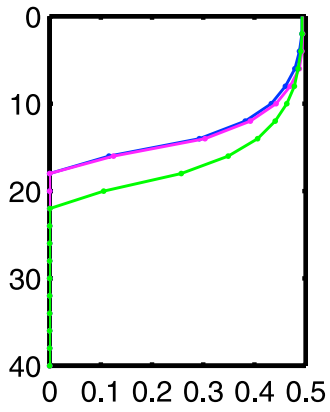

(f) $K_{h}\left(\mathrm{~m}^{2} \mathrm{~s}^{-1}\right)$

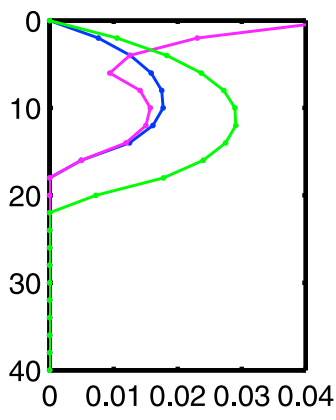

Figure 2. Comparisons of simulated (a) temperature profile $T$, (b) turbulence length scale $l$, (c) turbulence velocity magnitude $q$, (d) dissipation rate $\varepsilon$, (e) stability factor $S_{h}$, and (f) vertical diffusivity $K_{h}$ for experiments $\mathrm{W} 1-\mathrm{W} 3$ on day 5 .

results in a decrease in the SST (Figure 1) and an increase in the mixed layer depth (Figure 2a).

\subsection{Heating}

[19] For the heating experiments, the initial conditions and model parameters are set the same as those in the winddeepening experiments, except that the initial temperature from the surface to $100 \mathrm{~m}$ is a uniform $19^{\circ} \mathrm{C}$, and each experiment is forced with a constant wind stress of $0.1 \mathrm{~N} \mathrm{~m}^{-2}$ plus a heat flux of $290.4 \mathrm{~W} \mathrm{~m}^{-2}$ (i.e., $600 \mathrm{Ly} \mathrm{d}^{-1}$ ).

[20] Figure 3 depicts the model turbulence characteristics on day 2 in a similar fashion as shown in Figure 2 for experiments $\mathrm{W} 1-\mathrm{W} 3$. In experiment $\mathrm{H} 1$ (control run) and experiment $\mathrm{H} 2$ (wave breaking), there are large and unrealistic diffusivities below $25 \mathrm{~m}$ (Figure 3f). The possible reason is that their stratifications are close enough to the threshold of instability, thus generating a too large stability factor $S_{h}$ [Ezer, 2000].

[21] The temperature near the surface decreases slightly when the wave-breaking effect is considered (Figure 3a). The effects of wave breaking are quite sensitive to the magnitude of wind stress and the property of the mixed layer. Two additional groups of experiments are conducted to examine the wind stress effect. Under a weak wind condition (experiments Ha1-Ha3), the mixed layer is very shallow, so that wave breaking plays a role in regulating the temperature near the surface (Figure 4a). For example, the simulated SST in experiment Ha2 (wave breaking) is about $0.3^{\circ} \mathrm{C}$ lower than that in experiment Hal (control run) on day 2. Under strong winds, the wind-driven mixed layer is much deeper than the wave height, so that the wavebreaking effects are negligible (Figure 4b). On the other hand, if the mixed layer is weakly stratified under a strong surface heating condition, wave breaking can still affect the SST (Figure 3a).

[22] The effects of wave-turbulence interaction are also dependent on the wind stress magnitude. The TKE production induced by wave-turbulence interaction is a function of $u_{s 0} u_{*}^{2}$, and decays with the depth away from the surface in the form of $e^{2 k z}$ as in equation (7). Under the weak wind condition, the wave-turbulence interaction plays an important role in regulating the TKE budget and vertical mixing of the upper ocean (Figure 5a). The simulated SST in experiment $\mathrm{Ha} 3$ (wave-turbulence interaction) is about $1.5^{\circ} \mathrm{C}$ lower than that in experiment $\mathrm{Ha} 1$ on day 2 . Under high wind conditions, however, the shear production of TKE is much larger than that by wave-turbulence interaction (Figure 5b), so that wave-turbulence interaction has relatively little effect on the temperature in the upper ocean (Figure 4b).

\subsection{Cooling}

[23] For the cooling experiments, the initial conditions and the model parameters are the same as that for the winddeepening experiments. The models were forced by a constant wind stress of $0.1 \mathrm{~N} \mathrm{~m}^{-2}$ plus a heat flux of $-96.8 \mathrm{~W} \mathrm{~m}^{-2}$ (i.e., $-200 \mathrm{Ly} \mathrm{d}^{-1}$ ).

[24] Figure 6 shows the model results of day 5. It is obvious that the inclusion of wave-turbulence interaction increases the simulated $q$ and $\varepsilon$ throughout large depth (Figures $6 \mathrm{c}$ and $6 \mathrm{~d}$ ). The Richardson number $G_{h}$ is positive in the unstable stratification, so the increase of $q$ can decrease $G_{h}$, and the stability factor $S_{h}$ (Figure 6e). Thus, the effects of wave-turbulence interaction on the vertical dif- 
(a) $\mathrm{T}\left({ }^{\circ} \mathrm{C}\right)$

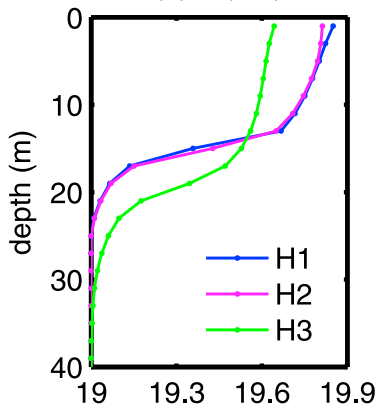

(b) $\mid(\mathrm{m})$

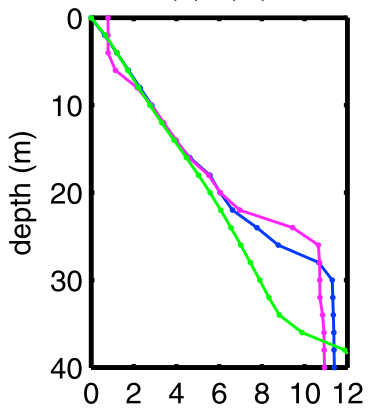

(c) $q\left(\mathrm{~m} \mathrm{~s}^{-1}\right)$

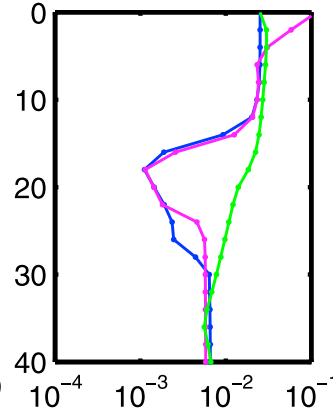

(d) $\varepsilon\left(\mathrm{m}^{2} \mathrm{~s}^{-3}\right)$

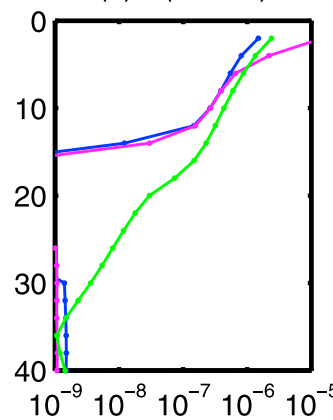

(e) $S_{h}$

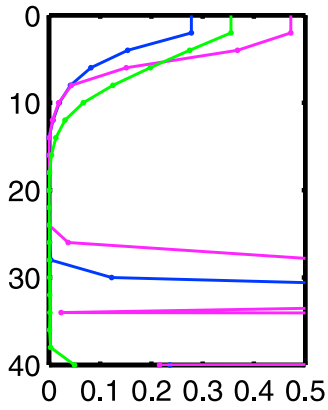

(f) $K_{h}\left(\mathrm{~m}^{2} \mathrm{~s}^{-1}\right)$

Figure 3. Same as Figure 2 except for experiments $\mathrm{H} 1-\mathrm{H} 3$ on day 2.

fusivity $K_{h}$ and on the upper ocean thermal structure are insignificant under unstable condition, as convective mixing dominates over all other processes (Figures 6a and 6f).

\section{One-Dimensional Experiments for Ocean Weather Station Papa}

[25] In this section, the model is tested against observational data from 9 June 2007 to 16 January 2008 taken from the ocean weather station Papa, which is located in the eastern North Pacific at $145^{\circ} \mathrm{W} 50^{\circ} \mathrm{N}$. Data from this station had served over the years as a measuring stick to evaluate various one-dimensional mixing models [Martin, 1985; Mellor, 2001; Mellor and Blumberg, 2004]. (a) $\tau=0.037 \mathrm{~N} \mathrm{~m}^{-2}$

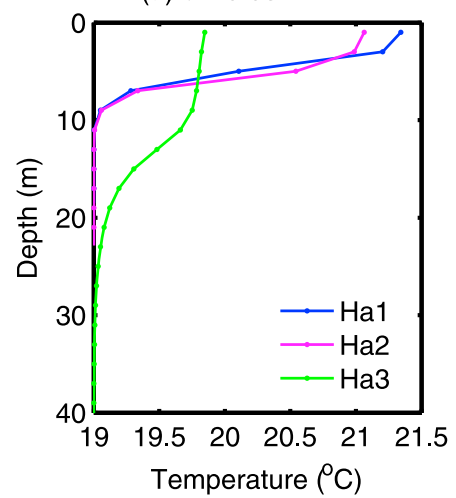

(b) $\tau=0.2 \mathrm{~N} \mathrm{~m}^{-2}$

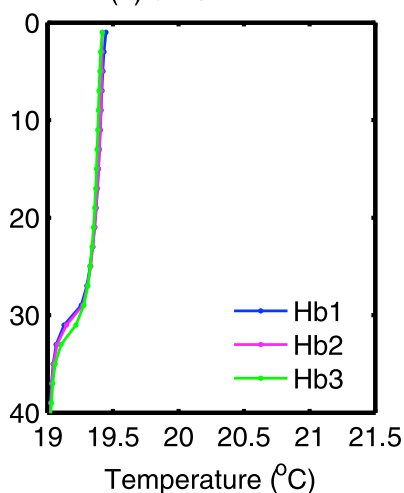

Figure 4. Same as Figure 3a except using surface wind stress of (a) $0.037 \mathrm{~N} \mathrm{~m}^{-2}$ and (b) $0.2 \mathrm{~N} \mathrm{~m}^{-2}$.

\subsection{Model Description}

[26] The model is the same as that used in section 3. The initial temperature and the salinity are taken from 9 June 2007, and linearly interpolated to the model grid; the initial velocity is set to zero. Hourly surface data are used to force the numerical model. The downward solar radiation and the long-wave radiation are taken from the observed 2 min high-resolution data. The rain data are taken from observed $10 \mathrm{~min}$ data. The sea surface albedo is taken from Payne [1972], and the seawater optical type is assumed to be Type II [Paulson and Simpson, 1977]. Upward long-wave radiation is obtained from the Stefan-Boltzmann law. The surface wind stress, the sensible heat flux, and the latent heat flux are obtained from the observed wind speed (Figure 7a), (a) Exp. $\mathrm{Ha} 3$

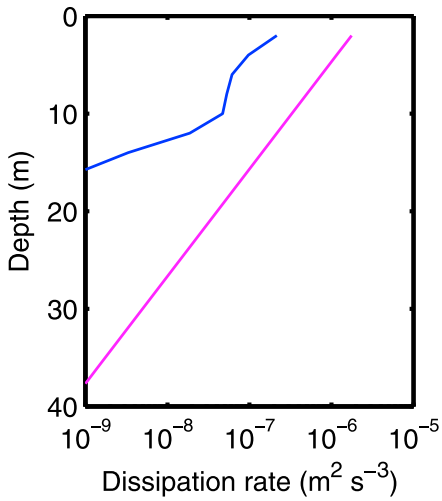

(b) Exp. $\mathrm{Hb} 3$

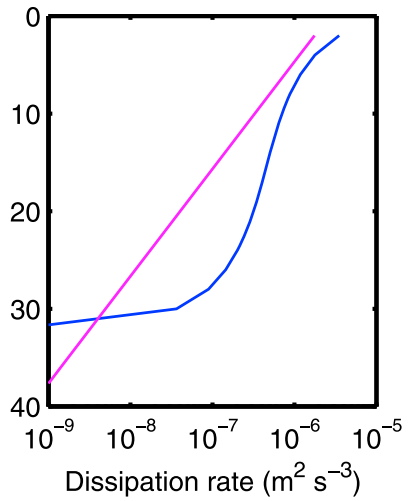

Figure 5. TKE productions caused by the velocity shear (blue lines) and wave-turbulence interaction (pink lines) on day 2 for (a) experiment $\mathrm{Ha} 3$ and (b) experiment $\mathrm{Hb} 3$. 
(a) $\mathrm{T}\left({ }^{\circ} \mathrm{C}\right)$

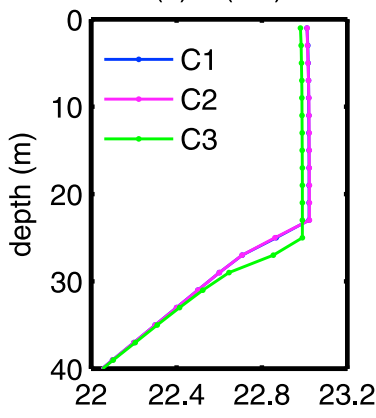

(b) $\mid(\mathrm{m})$

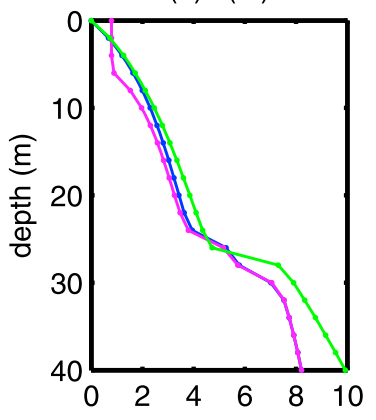

(c) $q\left(\mathrm{~m} \mathrm{~s}^{-1}\right)$

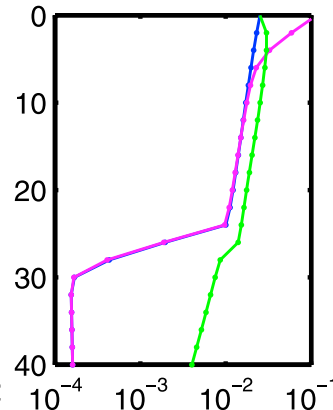

(d) $\varepsilon\left(\mathrm{m}^{2} \mathrm{~s}^{-3}\right)$

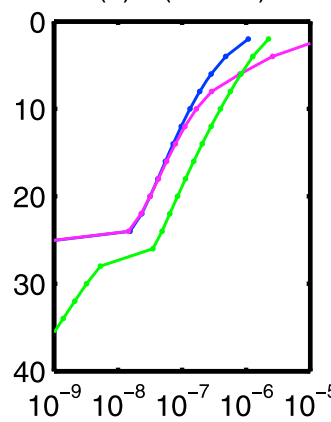

(e) $S_{h}$

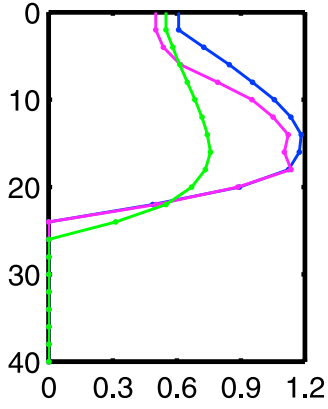

(f) $K_{h}\left(\mathrm{~m}^{2} \mathrm{~s}^{-1}\right)$

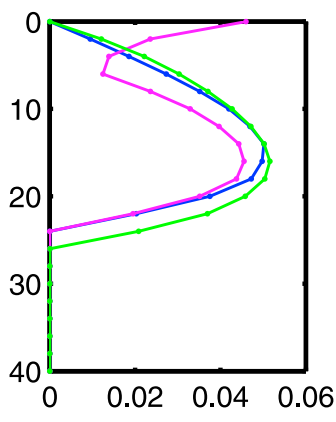

Figure 6. Same as Figure 2 except for experiments $\mathrm{C} 1-\mathrm{C} 3$ on day 5.

the SST, the air temperature, and the relative humidity using the COARE algorithm [Fairall et al., 2003]. Sea surface pressure data are not available, so pressure is simply set to $101.325 \mathrm{kPa}$. A net surface heat imbalance was found at this site, so $15 \mathrm{~W} \mathrm{~m}^{-2}$ is added to the outgoing heat flux to decrease the simulated deviation [Large et al., 1994]. In addition, the SST and the sea surface salinity (SSS) are relaxed to the observations, with relaxations of $50 \mathrm{~W} \mathrm{~m}^{-2}$ $\mathrm{K}^{-1}$ for SST and 30 days for SSS (assuming a mixed layer depth of $25 \mathrm{~m}$ ). The Coriolis parameter $f$ is for latitude of $50^{\circ} \mathrm{N}$, and the background mixing is set to $2 \times 10^{-6} \mathrm{~m}^{2} \mathrm{~s}^{-1}$ [Martin, 1985].

[27] Three cases are carried out: with and without wave breaking, and with wave-turbulence interaction (see Table 1). Surface wave characteristics are not available in the observations. Instead, the outputs from the WAVEWATCH III model are used [Tolman, 2002], as shown in Figures 7b and $7 \mathrm{c}$. The significant wave period is calculated by a linear formula $T_{s}=0.91 T_{p}$ [Wen et al., 1989], where $T_{p}$ is the peak wave period.

\subsection{Results}

[28] Figure 8 shows the simulated SST and MLD. The MLD is defined as the depth at which the temperature drops by $0.5^{\circ} \mathrm{C}$ from the surface. In experiment $\mathrm{P} 1$ (control run), the simulated SST from June to October is warmer while the MLD is shallower than the observations; this is a common problem of the classic M-Y scheme caused by the insufficient upper ocean mixing as mentioned before [Martin, 1985; Kantha and Clayson, 1994; Ezer, 2000]. In experiment P2 (wave breaking), the changes in SST and MLD are small compared to experiment $\mathrm{P} 1$. The results in experiment P3 (with wave-turbulence interaction), on the other hand, are in very good agreement with the observations in terms of the simulated SST and MLD. From November to January, there is a clear discrepancy between the model and the observations; possible reasons for that could be the absence of
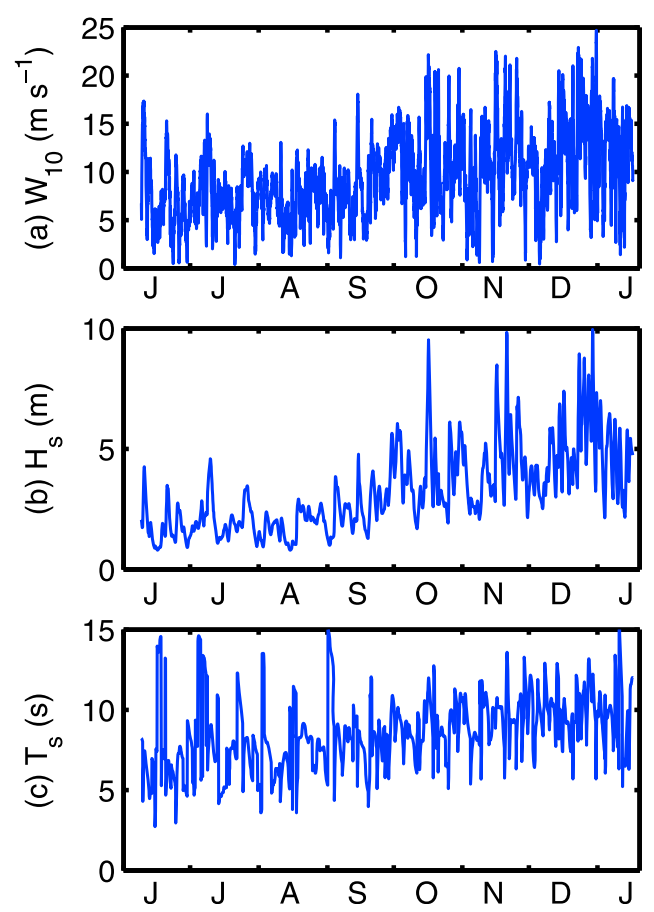

Figure 7. (a) Wind speed, (b) significant wave height, and (c) period at $50^{\circ} \mathrm{N}, 145^{\circ} \mathrm{W}$ from 9 June 2007 to 16 January 2008. The surface wave data were obtained from the WAVEWATCH III model. 
(a) $\operatorname{SST}\left({ }^{\circ} \mathrm{C}\right)$

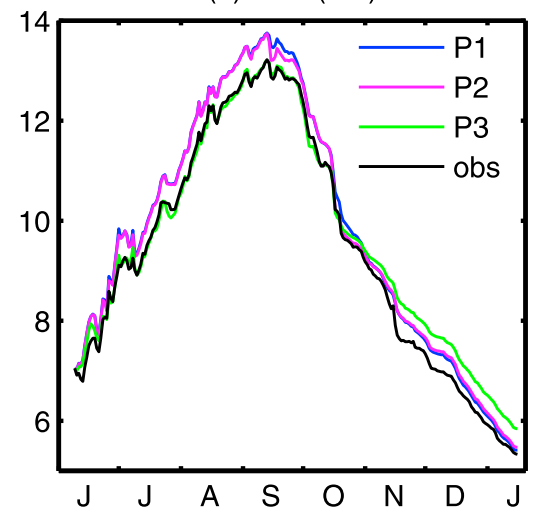

(b) MLD (m)

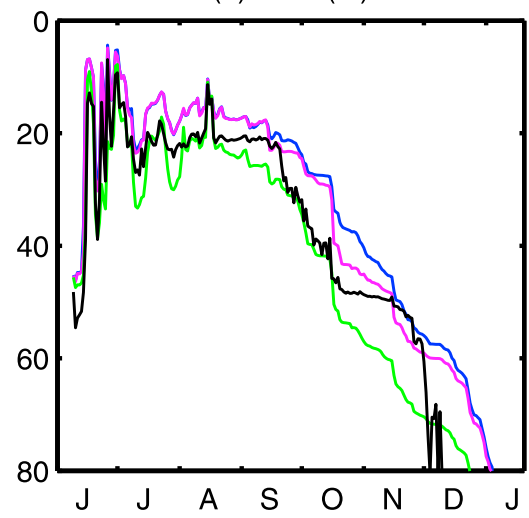

Figure 8. Simulated and observed daily mean (a) SST and (b) MLD at Station Papa from 9 June 2007 to 16 January 2008. The MLD is defined as the depth at which the temperature drops by $0.5^{\circ} \mathrm{C}$ from the surface.

advective processes in one-dimensional models and errors in the surface heat fluxes [Large et al., 1994].

[29] Too cold model subsurface temperature is another problem of the classic M-Y scheme, which is usually associated with a too shallow summertime thermocline [Ezer, 2000]. Figure 9 shows simulated and observed daily mean temperature profiles in the upper ocean. The simulated seasonal thermocline in experiment P1 is somewhat shallower and sharper than observed (Figures 9a and 9d), so that the subsurface temperature is significantly underestimated with a maximum bias of up to $-4^{\circ} \mathrm{C}$ (Figure 10a).

[30] At Station Papa, the shallowest MLD is about $20 \mathrm{~m}$, which is much deeper than that achieved by wave breaking. On the other hand, the temperature in the mixed layer is nearly uniform (Figure 9). As discussed in section 3, wave breaking alone has very little effect on the upper ocean thermal structure under these conditions. Thus, the simulated temperature profile and its deviation from observations in experiment $\mathrm{P} 2$ are quite similar to those in experiment $\mathrm{P} 1$ (Figures $9 \mathrm{~b}$ and 10b). As seen before, wave-turbulence interaction can affect greater depth than wave breaking, and thus the simulated seasonal thermocline is more realistic in experiment P3 (Figure 9c), with maximum temperature error of only $1{ }^{\circ} \mathrm{C}$ (Figure $10 \mathrm{c}$ ).

[31] These improvements of the upper ocean thermal structure can also be seen from Figure 11, which shows comparison of simulated and observed daily mean temperature profiles on 1 September 2007 and 1 October 2007, respectively. In experiment $\mathrm{P} 1$, the simulated surface temperature is overestimated, while the subsurface temperature (a) Temperature: P1

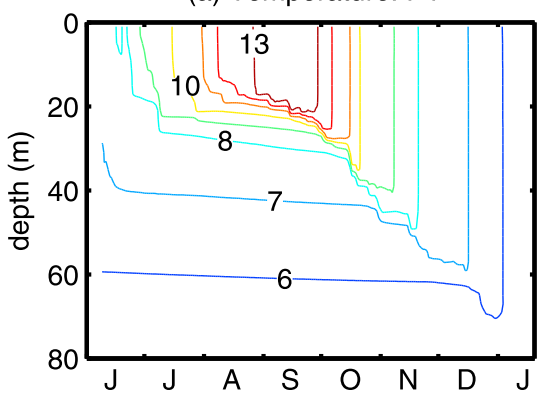

(c) Temperature: P3

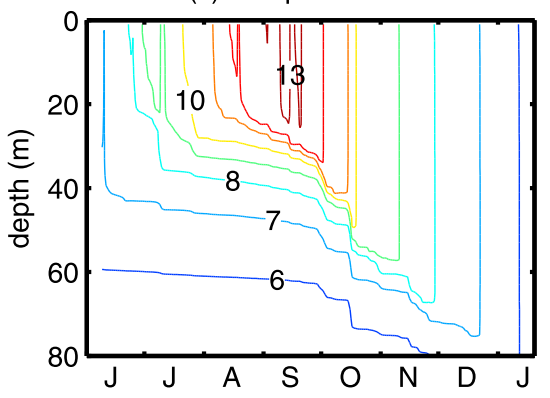

(b) Temperature: P2

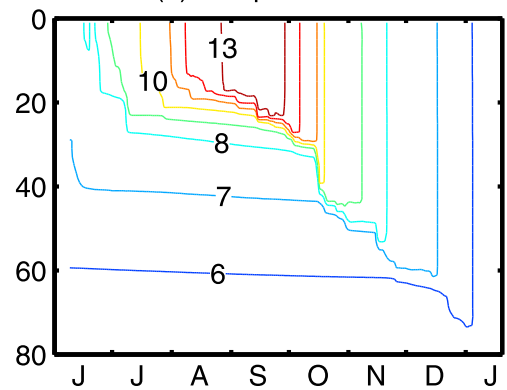

(d) Observed temperature

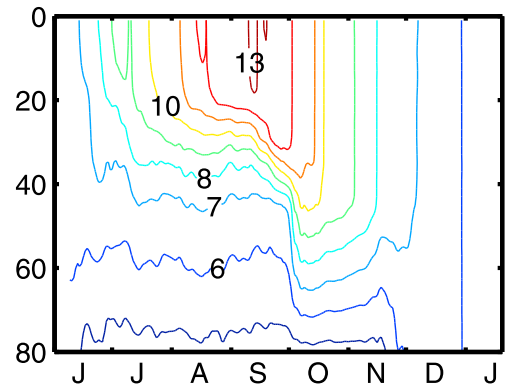

Figure 9. Simulated and observed daily mean temperature profiles (units in ${ }^{\circ} \mathrm{C}$ ) from (a) experiment $\mathrm{P} 1$, (b) experiment P2, (c) experiment P3, and (d) observations. 
(a) Temperature anomaly: P1

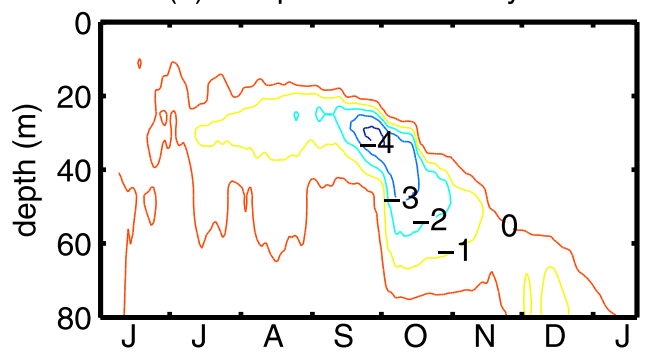

(b) Temperature anomaly: P2

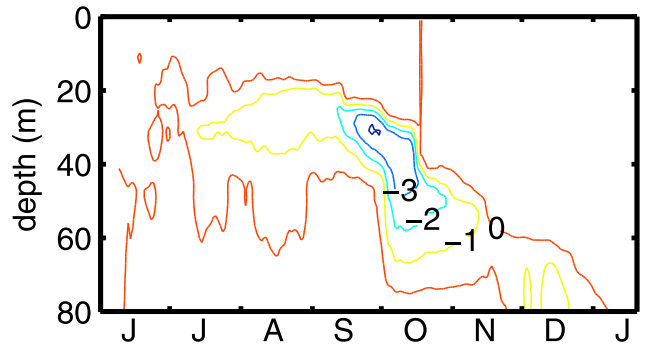

(c) Temperature anomaly:P3

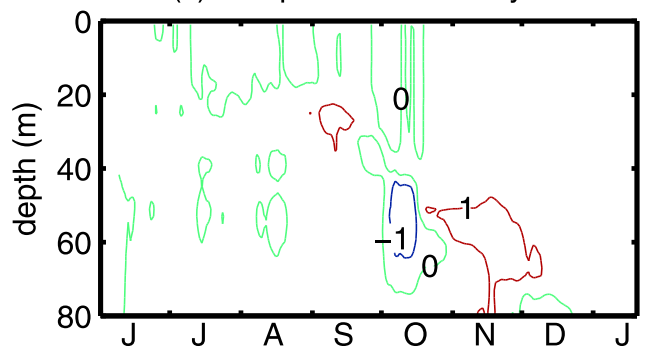

Figure 10. Simulated daily mean temperature deviations from the observation (units in ${ }^{\circ} \mathrm{C}$ ) from (a) experiment $\mathrm{P} 1$, (b) experiment P2, and (c) experiment P3.

is underestimated. Meanwhile, the MLD is about $4-10 \mathrm{~m}$ shallower than the observations. These biases are attributed to insufficient mixing (Figure 12), which prevents the heat transport from the surface layer to the subsurface. A large amount of heat accumulates in the surface, which results in the simulated temperature being too warm in the surface, while too cold in the subsurface.

[32] Wave breaking can greatly enhance the turbulence and the vertical mixing too. However, the wave-breaking effect is limited to the near-surface layer, so that it is insignificant in regions with a deep MLD. The TKE dissipation rate induced by the wave-turbulence interaction, however, decays in the form of $e^{2 k z}$ away from the surface, so that it can affect the depth much greater than that of wave breaking, especially for the long swells with small wave numbers. The observations also show that strong turbulence can extend to tens of meters in the ocean when swells are present [Anis and Moum, 1995]. Moreover, the swells can radiate away from their generation areas and propagate over a large distance across an ocean basin. The wave-turbulence interaction should be a nonnegligible TKE source in regions where the wind is weak but the swell is strong.

[33] In the experiments, when the wave-turbulence interaction is incorporated into the model, the simulated vertical mixing is greatly enhanced (Figure 12). Strong mixing can transport a large amount of heat from the surface layer to the subsurface, resulting in a decrease in the surface temperature and an increase in subsurface temperature (Figure 11). Thus, the temperature distribution of the upper ocean is improved greatly in experiment $\mathrm{P} 3$ due to the effect of wave-turbulence interaction and the simulated temperature is close to the observed temperature.

\section{Global Ocean General Circulation Model}

[34] The behavior of the $\mathrm{M}-\mathrm{Y}$ scheme in three-dimensional models is sometimes different from that in one-dimensional models due to horizontal advection and other threedimensional processes (e.g., Mellor [2001] discussed some of these limitations). This section examines effects of the wave-turbulence interaction and wave breaking on upper ocean simulations by the Princeton Ocean Model (POM) [Blumberg and Mellor, 1987].

\subsection{Model Description}

[35] The model domain covers the global ocean between $72^{\circ} \mathrm{S}$ and $65^{\circ} \mathrm{N}$ with a zonal resolution of $1^{\circ}$. The meridional resolution is $1 / 3^{\circ}$ within $10^{\circ} \mathrm{S}-10^{\circ} \mathrm{N}$ and increases linearly (a) temperature $\left({ }^{\circ} \mathrm{C}\right)$ : Sep 1

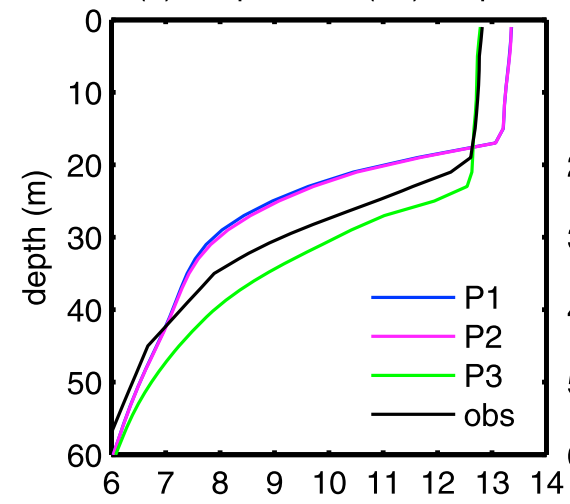

(b) temperature $\left({ }^{\circ} \mathrm{C}\right)$ : Oct 1

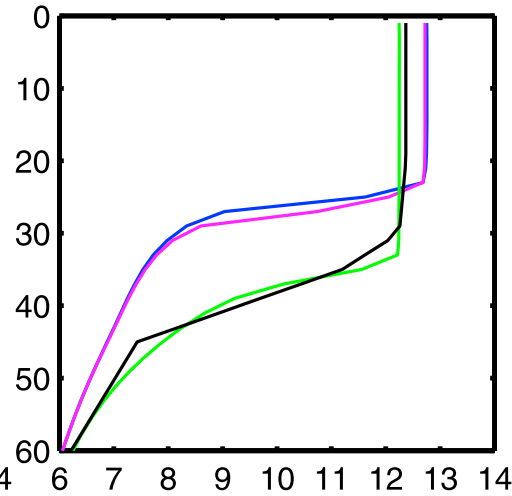

Figure 11. Simulated and observed daily mean temperature profiles at Station Papa (units in ${ }^{\circ} \mathrm{C}$ ) on (a) 1 September 2007 and (b) 1 October 2007. 


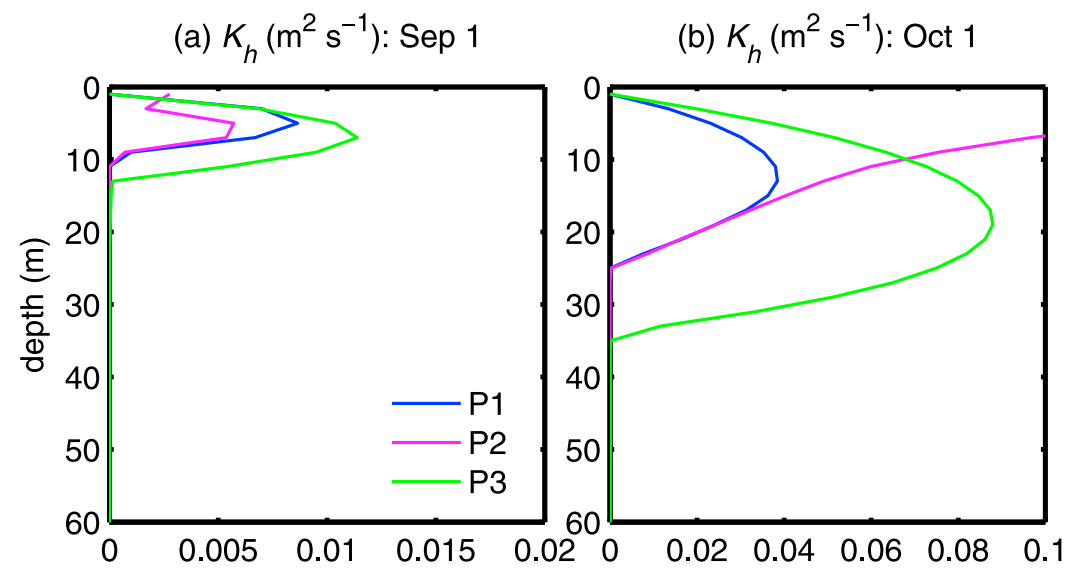

Figure 12. Simulated daily mean vertical diffusivity profiles (units in $\mathrm{m}^{2} \mathrm{~s}^{-1}$ ) on (a) 1 September 2007 and (b) 1 October 2007.

to $1^{\circ}$ by $20^{\circ} \mathrm{N}\left(20^{\circ} \mathrm{S}\right)$. The model has 32 sigma layers in the vertical direction, with at least 6 layers in the top $60 \mathrm{~m}$ and at least 10 additional levels between 60 and $250 \mathrm{~m}$. The bottom topography is obtained from ETOPO5, and the maximum water depth is set as $5000 \mathrm{~m}$.

[36] The model is initiated with the temperature and the salinity conditions in January taken from the WOA01 climatology [Conkright et al., 2002]. The climatological monthly mean wind stress is taken from the QuickSCAT/ NCEP blended ocean winds from 2000 to 2005 [Milliff et $a l ., 2004]$. The surface heat flux and the freshwater flux are taken from the monthly mean COADS climatology $[d a$ Silva et al., 1994]. The penetration of the solar radiation is taken into account, and the seawater optical type is taken as Type I [Paulson and Simpson, 1977]. Moreover, to keep surface density values from drifting too far from climatology, the SST and the SSS are relaxed to the monthly mean climatology of WOA 01 , with a relaxation of $50 \mathrm{~W} \mathrm{~m} \mathrm{~m}^{-2} \mathrm{~K}^{-1}$ for SST and 60 days for SSS (for a mixed layer depth of $25 \mathrm{~m}$ ). Sponge layers of $5^{\circ}$ are placed along the northern and the southern boundaries, in which both temperature and salinity are relaxed toward observed monthly climatological fields.

[37] The horizontal viscosity and the diffusion are calculated by a Smagorinsky-type formula [Smagorinsky, 1963], but the minimum horizontal viscosity is set to $2 \times 10^{3} \mathrm{~m}^{2} \mathrm{~s}^{-1}$ [Pezzi and Richards, 2003]. A time-splitting scheme is used, with a barotropic time step (for the vertically averaged equations) of $60 \mathrm{~s}$ and a baroclinic time step (for the 3D equations) of $1200 \mathrm{~s}$. The vertical viscosity and the diffusivity are calculated from the level 2.5 turbulence closure scheme [Mellor and Yamada, 1982], with background coefficients of $1 \times 10^{-4}$ and $1 \times 10^{-5} \mathrm{~m}^{2} \mathrm{~s}^{-1}$, respectively. Three experiments (experiments G1-G3) are carried out (Table 1). The three numerical experiments are run for 10 years from rest (cold start), in which the outputs of the last year are used for the analysis. Similar to experiment P3, surface wave characteristics in experiment G3 are also obtained from the outputs from the WAVEWATCH III model [Tolman, 2002].

\subsection{Results}

[38] The most outstanding features induced by the wave breaking and wave-turbulence interaction are improvements of the subsurface thermal structure during summer. Figure 13 shows monthly mean temperature differences along the dateline in August of the three experiments relative to the WOA01 data. In experiment G1 (control run), the simulated subsurface temperature between $20^{\circ} \mathrm{N}$ and $60^{\circ} \mathrm{N}$ is seriously underestimated by insufficient mixing as compared to the

(a) Temperature difference along $180^{\circ} \mathrm{E}$ in August: Exp G1

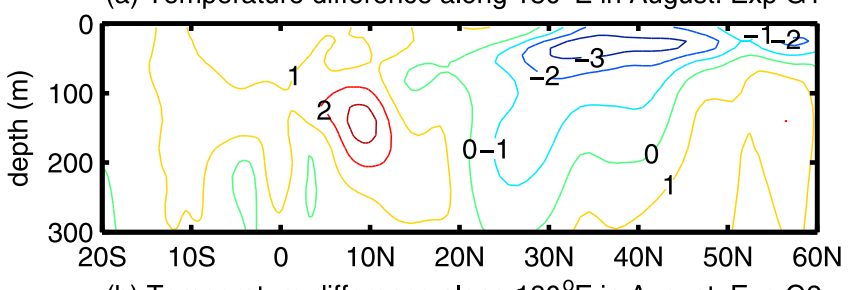

(b) Temperature difference along $180^{\circ} \mathrm{E}$ in August: Exp G2

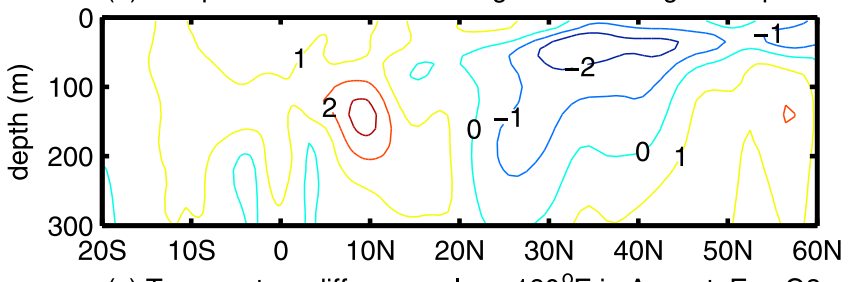

(c) Temperature difference along $180^{\circ} \mathrm{E}$ in August: Exp G3

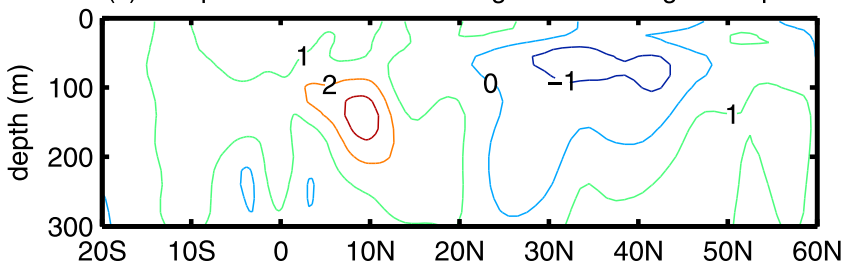

Figure 13. Monthly mean temperature differences from the climatology along the dateline in August from (a) experiment G1, (b) experiment G2, and (c) experiment G3. Contour interval is $1^{\circ} \mathrm{C}$. 
(a) Temperature difference along $30^{\circ} \mathrm{N}$ in August: Exp G1

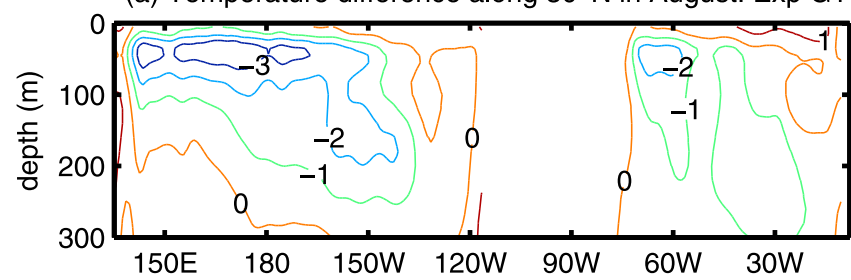

(b) Temperature difference along $30^{\circ} \mathrm{N}$ in August: Exp G2

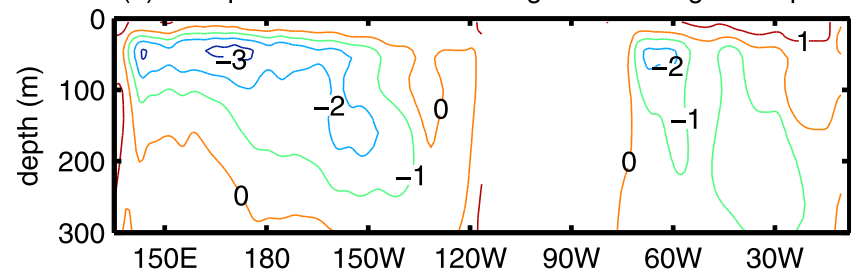

(c) Temperature difference along $30^{\circ} \mathrm{N}$ in August: Exp G3

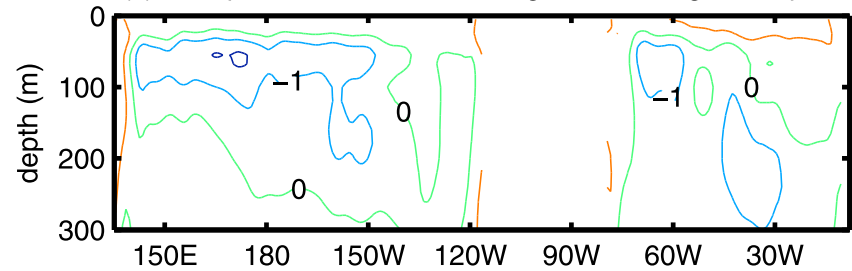

Figure 14. Monthly mean temperature differences from the climatology along $30^{\circ} \mathrm{N}$ in August from (a) experiment G1, (b) experiment G2, and (c) experiment G3. Contour interval is $1^{\circ} \mathrm{C}$. observations, with a maximum bias up to $3^{\circ} \mathrm{C}$ (Figure 13a). The temperature biases in experiment G2 (wave breaking) are quite similar to that in experiment G1, but their amplitudes seem to be reduced slightly due to the enhanced mixing of wave breaking (Figure 13b). Although it is believed that the mixing induced by wave breaking is mainly limited to the upper few meters, its effect can extend to a greater depth in the three-dimensional model, compared with the more limited impact seen in the one-dimensional model discussed before.

[39] When the wave-turbulence interaction is incorporated into the 3D model, the simulation of the upper ocean temperature is significantly improved. The biases are less than $1^{\circ} \mathrm{C}$ in most areas. The improvements can also be seen from Figure 14, which shows the monthly mean model temperature errors along $30^{\circ} \mathrm{N}$ in August for the three experiments.

[40] The improvements in experiments G2 and G3 are mainly located in the middle and the high latitudes. In the low latitudes, the influences of wave breaking and waveturbulence interaction are less important. This is attributed to the fact that wave energy is smaller in tropical areas [Wang and Huang, 2004]. The other reason may be due to the fact that the turbulence production in the ocean mixed layer is dominated by TKE flux from the sea surface in the extratropical ocean, while it is dominated by shear production in the equatorial ocean [Noh, 2004].

[41] Figure 15 shows the temperature profiles at the central point of the North Pacific $\left(30^{\circ} \mathrm{N}, 180^{\circ} \mathrm{E}\right)$. In summer, the seasonal thermocline usually appears under the mixed layer (a) Temperature profile: Exp G1

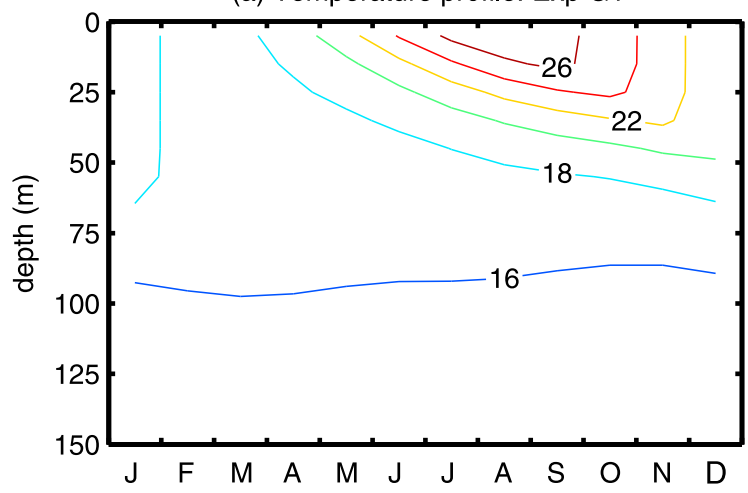

(c) Temperature profile: Exp G3

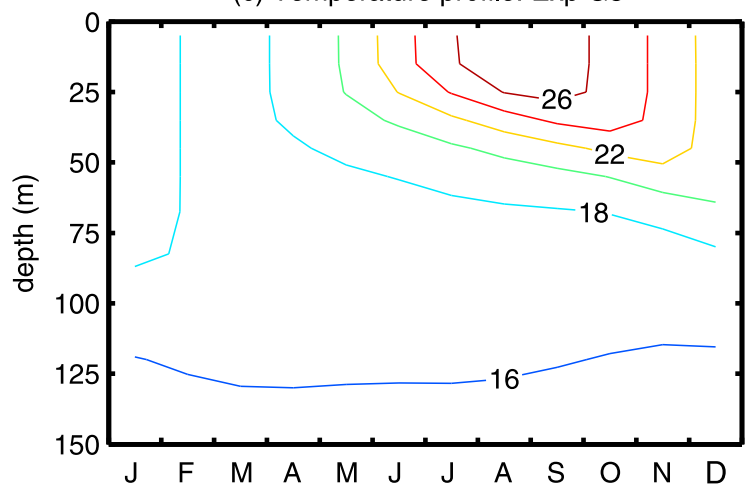

(b) Temperature profile: Exp G2

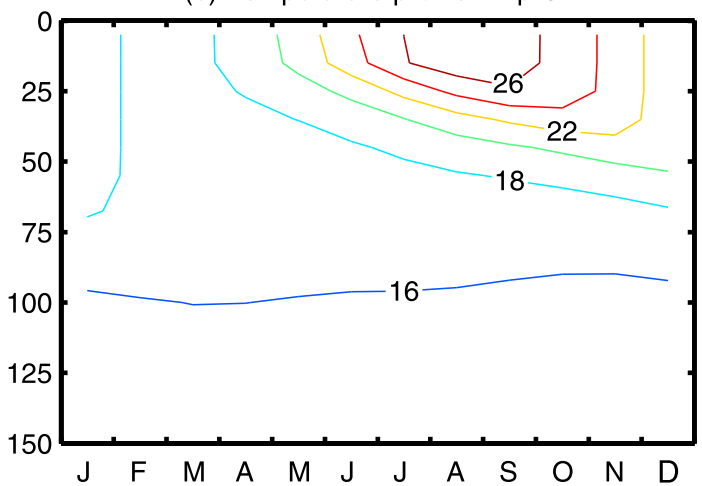

(d) Temperature profile: WOA01

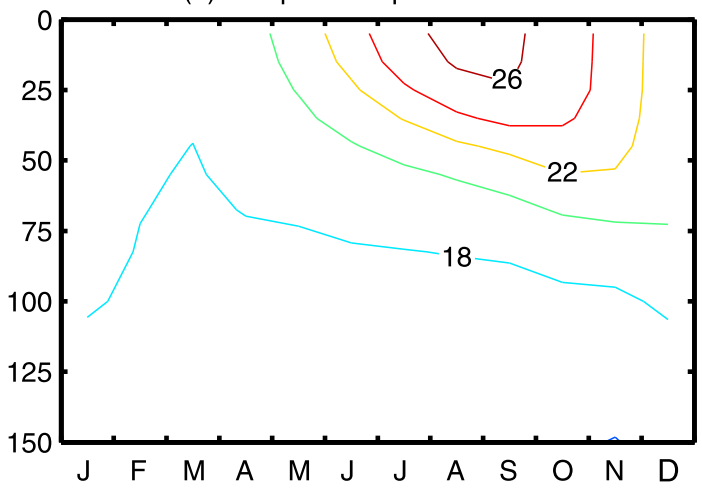

Figure 15. Monthly mean temperature as a function of depth and time at $30^{\circ} \mathrm{N}, 180^{\circ} \mathrm{E}$ from (a) experiment G1, (b) experiment G2, (c) experiment G3, and (d) the climatology. Contour interval is $2^{\circ} \mathrm{C}$. 
(a) Temperature anomaly profile: Exp G1

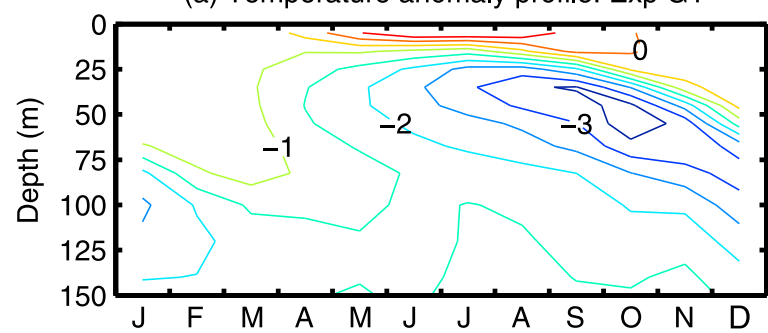

(b) Temperature anomaly profile: Exp G2

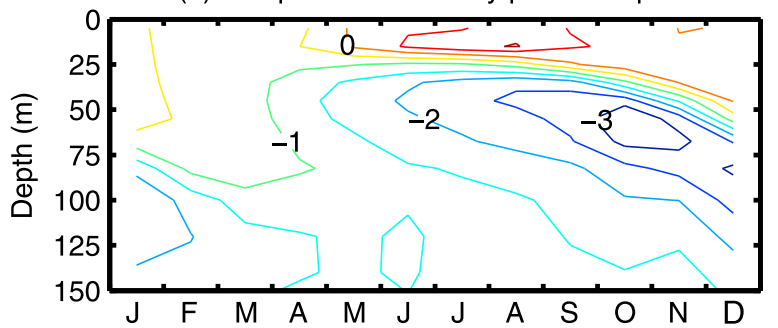

(c) Temperature anomaly profile: $\operatorname{Exp} \mathrm{G} 3$

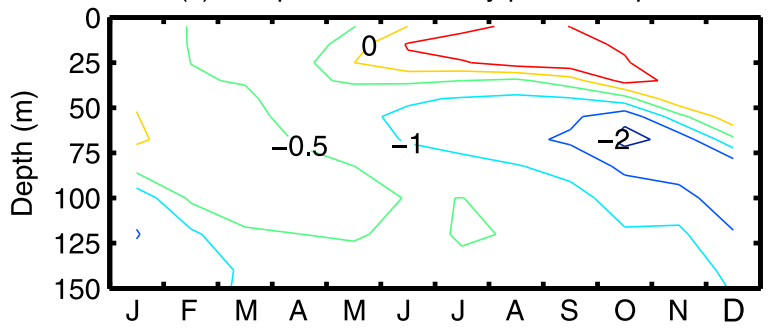

Figure 16. Same as Figure 15 except for monthly mean temperature anomalies from the WOA01 climatology. Contour interval is $0.5^{\circ} \mathrm{C}$.

at the middle and the high latitudes due to strong solar radiation and weak wind, while in winter, the mixed layer deepens and the seasonal thermocline disappears due to the strong cooling-induced convection. The too shallow summer thermocline associated with insufficient mixing is a common problem of ocean general circulation models with the M-Y scheme. Ezer [2000] suggested that shortwave radiation penetration can improve the simulation, which can then reproduce a more realistic summer thermocline. However, the thermocline depth is still underestimated to some extent in his model. Similar to his study, the seasonal thermocline is somewhat shallow in experiment G1, although the model has included shortwave radiation penetration effect. This shallow thermocline results in the simulated temperature in summer being seriously underestimated in the subsurface with a maximum bias of $3.5^{\circ} \mathrm{C}$, while overestimated in the surface (Figure 16a).

[42] In experiment G2, the simulated thermocline seems to be slightly improved due to the wave-breaking effect (Figure 15b), and the temperature biases decrease slightly compared to that in experiment G1 (Figure 16b). In experiment G3, the seasonal thermocline is greatly improved by including the wave-turbulence interaction (Figure 15c), and the maximum deviation from the climatology decreases to $2.0^{\circ} \mathrm{C}$ (Figure 16c). This indicates that other improvements, such as more realistic surface forcing [Ezer, 2000], a Richardson-number-dependent dissipation correction
[Mellor, 2001], and internal wave breaking [Kantha and Clayson, 1994], may also be needed to simulate the upper ocean accurately.

\section{Conclusions}

[43] Wind energy input into ocean surface waves is a dominant source of external mechanical energy for the ocean [Ferrari and Wunsch, 2009]. Surface waves can transfer TKE from wavefields to the turbulence via wave breaking and wave-turbulence interaction. This energy transfer exerts important influence on the TKE budget of the upper ocean. In this study, the effects of wave breaking and wave-turbulence interaction on the M-Y scheme and upper ocean simulations are examined and compared with each other using one-dimensional and three-dimensional ocean circulation models.

[44] The classic M-Y scheme is obtained for stratified boundary layers near rigid surfaces, in which the effects of surface waves are missing [Mellor and Yamada, 1982]. Although the scheme can successfully reproduce the general features of the ocean, there are usually systematic deficiencies due to insufficient mixing in the upper ocean: the simulated temperature in summer is often too high near the surface, while too low in the subsurface associated with too shallow MLD and seasonal thermocline [Martin, 1985; Ezer, 2000].

[45] Although a large amount of wave energy is lost via breaking, its induced turbulence and mixing are mainly limited to the upper few meters. Furthermore, to account for surface wave breaking in ocean models will require an extremely fine resolution near the surface [Mellor and Blumberg, 2004]; such high resolution is not possible in most general ocean circulation models. In regions with weak wind and strong surface heating, the mixed layer is usually shallow with weak stratification. Wave breaking may play a role in the behavior of the temperature near the surface, but its effects are very confined. Under moderate and high wind conditions, the mixed layer is usually much deeper than the depth affected by wave breaking, so that wave-breaking effects are negligible.

[46] The wave-turbulence interaction can affect much greater depths than wave breaking. The wave-turbulence interaction can be incorporated into the $\mathrm{M}-\mathrm{Y}$ scheme as an additional TKE production, and other empirical constants need not to be adjusted. The results show that the waveturbulence interaction can effectively amend the problem of insufficient mixing in the classic $M-Y$ scheme. In the models with the improved M-Y scheme, where the waveturbulence interaction is added, the behavior of the M-Y scheme, as well as the simulated upper ocean thermal structure, is significantly improved as compared to that by the classic M-Y scheme. In summary, the results clearly demonstrate that the effects of the wave-turbulence interaction on the upper ocean are in most cases more important than those of wave breaking; these results are due to two main reasons: (1) the large depth affected by the waveturbulence interaction and (2) the impact of a nonlocally generated swell in the wave-turbulence interaction. 
[47] Acknowledgments. This work was supported by the National Natural Science Foundation of China through grants 40806017 and 40730842 and the National Basic Research Program of China (973 Program) through grant 2010 CB950501. T.E. was partially supported by grants from NSF, MMS, and NOAA. The authors thank the Papa Project Office for providing in situ data (http://www.pmel.noaa.gov/stnP/data.html) and NOAA/NWS/NCEP for providing the data of the WAVEWATCH III model (http://polar.ncep.noaa.gov/waves/index2.shtml).

\section{References}

Agrawal, Y. C., E. A. Terray, M. A. Donelan, P. A. Hwang, A. J. Williams III, W. M. Drennan, K. K. Kahma, and S. A. Kitaigorodskii (1992), Enhanced dissipation of kinetic energy beneath surface waves, Nature, 359, 219-220, doi:10.1038/359219a0.

Anis, A., and J. N. Moum (1995), Surface wave-turbulence interactions: Scaling $\varepsilon(z)$ near the sea surface, J. Phys. Oceanogr., 25, 2025-2045, doi:10.1175/1520-0485(1995)025<2025:SWISNT>2.0.CO;2.

Ardhuin, F., and A. D. Jenkins (2006), On the interaction of surface waves and upper ocean turbulence, J. Phys. Oceanogr., 36, 551-557, doi:10.1175/JPO2862.1.

Babanin, A. V., and B. K. Haus (2009), On the existence of water turbulence induced by nonbreaking surface waves, J. Phys. Oceanogr., 39, 2675-2679, doi:10.1175/2009JPO4202.1.

Blumberg, A. F., and G. L. Mellor (1987), A description of a three-dimensional coastal ocean circulation model, in Three-Dimensional Coastal Ocean Models, Coastal Estuarine Ser., vol. 4, edited by N. Heaps, pp. 1-16, AGU, Washington, D. C.

Burchard, H. (2001), Simulating the wave-enhanced layer under breaking surface waves with two-equation turbulence models, J. Phys. Oceanogr., 31, 3133-3145, doi:10.1175/1520-0485(2001)031<3133:STWELU >2.0 $\mathrm{CO} ; 2$.

Cheung, T. K., and R. L. Street (1988), The turbulent layer in the water at an air-water interface, J. Fluid Mech., 194, 133-151, doi:10.1017/ S0022112088002927.

Conkright, M. E., R. A. Locarnini, H. E. Garcia, T. O’Brien, T. P. Boyer, C. Stephens, and J. I. Antonov (2002), World Ocean Atlas 2001: Objective analyses, data statistics, and figures [CD-ROM], Intern. Rep. 17, 17 pp., Natl. Oceanogr. Data Cent., Silver Spring, Md.

Craig, P. D., and M. L. Banner (1994), Modeling wave-enhanced turbulence in the ocean surface layer, J. Phys. Oceanogr., 24, 2546-2559, doi:10.1175/1520-0485(1994)024<2546:MWETIT>2.0.CO;2.

Dai, D. J., F. Qiao, W. Sulisz, L. Han, and A. Babanin (2010), An experiment on the nonbreaking surface-wave-induced vertical mixing, J. Phys. Oceanogr., 40, 2180-2188, doi:10.1175/2010JPO4378.1.

D'Alessio, S. J. D., K. Abdella, and N. A. McFarlane (1998), A new secondorder turbulence closure scheme for modeling the oceanic mixed layer, J. Phys. Oceanogr., 28, 1624-1641, doi:10.1175/1520-0485(1998) $028<1624$ :ANSOTC $>2.0 . \mathrm{CO} ; 2$.

da Silva, A. M., C. C. Young-Molling, and S. Levitus (Eds.) (1994), Atlas of Surface Marine Data 1994, vol. 1, Algorithms and Procedures, NOAA Atlas NESDIS, vol. 6, 83 pp., NOAA, Silver Spring, Md.

Donelan, M. A. (1998), Air-water exchange processes, in Physical Processes in Lakes and Oceans, Coastal Estuarine Stud. Ser., vol. 54, edited by J. Imberger, pp. 19-36, AGU, Washington, D. C.

Drennan, W. M., M. A. Donelan, E. A. Terray, and K. B. Katsaros (1996), Oceanic turbulence dissipation measurements in SWADE, J. Phys. Oceanogr., 26, 808-815, doi:10.1175/1520-0485(1996)026<0808:OTDMIS $>2.0 \mathrm{CO} \cdot 2$

Ezer, T. (2000), On the seasonal mixing layer simulated by a basin-scale ocean model and the Mellor-Yamada turbulence scheme, J. Geophys. Res., 105, 16,843-16,855, doi:10.1029/2000JC900088.

Fairall, C. W., E. F. Bradley, J. E. Hare, A. A. Grachev, and J. B. Edson (2003), Bulk parameterization of air-sea fluxes: Updates and verification for the COARE algorithm, J. Clim., 16, 571-591, doi:10.1175/15200442(2003)016<0571:BPOASF $>2.0 . \mathrm{CO} ; 2$.

Ferrari, R., and C. Wunsch (2009), Ocean circulation kinetic energy: Reservoirs, sources, and sinks, Annu. Rev. Fluid Mech., 41, 253-282, doi:10.1146/annurev.fluid.40.111406.102139.

Gemmrich, J. R., and D. M. Farmer (2004), Near-surface turbulence in the presence of breaking waves, J. Phys. Oceanogr., 34, 1067-1086, doi:10.1175/1520-0485(2004)034<1067:NTITPO >2.0.CO;2.

Huang, C. J., and F. Qiao (2010), Wave-turbulence interaction and its induced mixing in the upper ocean, J. Geophys. Res., 115, C04026, doi:10.1029/2009JC005853.

Huang, C. J., F. Qiao, and Z. Song (2008), The effect of the wave-induced mixing on the upper ocean temperature in a climate model, Acta Oceanol. Sin., 27, 104-111.
Kantha, L. H., and C. A. Clayson (1994), An improved mixed layer model for geophysical applications, J. Geophys. Res., 99, 25,235-25,266, doi:10.1029/94JC02257.

Kantha, L. H., and C. A. Clayson (2004), On the effect of surface gravity waves on mixing in the oceanic mixed layer, Ocean Modell., 6, 101-124, doi:10.1016/S1463-5003(02)00062-8.

Kitaigorodskii, S. A., M. A. Donelan, J. L. Lumley, and E. A. Terray (1983), Wave-turbulence interaction in the upper ocean. Part II: Statistical characteristics of wave and turbulence components of the random velocity field in the marine surface layer, J. Phys. Oceanogr., 13 , 1988-1999, doi:10.1175/1520-0485(1983)013<1988:WTIITU $>2.0$. $\mathrm{CO} ; 2$.

Large, W. G., J. C. McWilliams, and S. C. Doney (1994), Oceanic vertical mixing: A review and a model with a nonlocal boundary layer parameterization, Rev. Geophys., 32, 363-403, doi:10.1029/94RG01872.

Lin, X., S.-P. Xie, X. Chen, and L. Xu (2006), A well-mixed warm water column in the central Bohai Sea in summer: Effects of tidal and surface wave mixing, J. Geophys. Res., 111, C11017, doi:10.1029/ 2006JC003504.

Martin, P. J. (1985), Simulation of the mixed layer at OWS November and Papa with several models, J. Geophys. Res., 90, 903-916, doi:10.1029/ JC090iC01p00903.

Mellor, G. L. (2001), One-dimensional, ocean surface modeling, a problem and a solution, J. Phys. Oceanogr., 31, 790-809, doi:10.1175/1520-0485 (2001)031<0790:ODOSLM $>2.0$.CO;2.

Mellor, G., and A. Blumberg (2004), Wave breaking and ocean surface layer thermal response, J. Phys. Oceanogr., 34, 693-698, doi:10.1175 2517.1.

Mellor, G., and T. Yamada (1982), Development of a turbulence closure model for geophysical fluid problems, Rev. Geophys., 20, 851-875, doi:10.1029/RG020i004p00851.

Milliff, R. F., J. Morzel, D. B. Chelton, and M. H. Freilich (2004), Wind stress curl and wind stress divergence biases from rain effects on QSCAT surface wind retrievals, J. Atmos. Oceanic Technol., 21, 1216-1231, doi:10.1175/1520-0426(2004)021<1216:WSCAWS >2.0.CO;2.

Noh, Y. (2004), Sensitivity to wave breaking and the Prandtl number in the ocean mixed layer model and its dependence on latitude, Geophys. Res. Lett., 31, L23305, doi:10.1029/2004GL021289.

Paulson, C. A., and J. J. Simpson (1977), Irradiance measurements in the upper ocean, J. Phys. Oceanogr., 7, 952-956, doi:10.1175/1520-0485 $(1977) 007<0952$ :IMITUO $>2.0 . \mathrm{CO} ; 2$

Payne, R. E. (1972), Albedo of the sea surface, J. Atmos. Sci., 29, 959-970, doi:10.1175/1520-0469(1972)029<0959:AOTSS > 2.0.CO;2.

Pezzi, L. P., and K. J. Richards (2003), Effects of lateral mixing on the mean state and eddy activity of an equatorial ocean, J. Geophys. Res. 108(C12), 3371, doi:10.1029/2003JC001834

Phillips, O. M. (1961), A note on the turbulence generated by gravity waves, J. Geophys. Res., 66, 2889-2893, doi:10.1029/JZ066i009p02889. Qiao, F., Y. Yuan, Y. Yang, Q. Zheng, C. Xia, and J. Ma (2004), Waveinduced mixing in the upper ocean: Distribution and application to a global ocean circulation model, Geophys. Res. Lett., 31, L11303, doi:10.1029/2004GL019824.

Qiao, F., Y. Yuan, T. Ezer, C. Xia, Y. Yang, X. Lü, and Z. Song (2010), A three-dimensional surface wave-ocean circulation coupled model and its initial testing, Ocean Dyn., 60, 1339-1355, doi:10.1007/s10236-0100326-y.

Rapp, R. J., and W. K. Melville (1990), Laboratory measurements of deepwater breaking waves, Philos. Trans. R. Soc. London A, 331, 735-800, doi:10.1098/rsta.1990.0098.

Rascle, N., F. Ardhuin, P. Queffeulou, and D. Croizé-Fillon (2008), A global wave parameter database for geophysical applications. Part 1: Wave-current-turbulence interaction parameters for the open ocean based on traditional parameterizations, Ocean Modell., 25, 154-171, doi:10.1016/j.ocemod.2008.07.006.

Smagorinsky, J. (1963), General circulation experiments with the primitive equations: I. The basic experiment, Mon. Weather Rev, 91, 99-164, doi:10.1175/1520-0493(1963)091<0099:GCEWTP>2.3.CO;2.

Soloviev, A., and R. Lukas (2003), Observation of wave-enhanced turbulence in the near-surface layer of the ocean during TOGA COARE, Deep Sea Res. Part I, 50, 371-395, doi:10.1016/S0967-0637(03)00004-9.

Song, Z., F. Qiao, Y. Yang, and Y. Yuan (2007), An improvement of the too cold tongue in the tropical Pacific with the development of an oceanwave-atmosphere coupled numerical model, Prog. Nat. Sci., 17, 576-583, doi:10.1080/10020070708541038

Sun, Q., J. Song, and C. Guan (2005), Simulation of the ocean surface mixed layer under the wave breaking, Acta Oceanol. Sin., 24, 9-15.

Teixeira, M. A. C., and S. E. Belcher (2002), On the distortion of turbulence by a progressive surface wave, J. Fluid Mech., 458, 229-267, doi: $10.1017 / \mathrm{S} 0022112002007838$ 
Tolman, H. L. (2002), User manual and system documentation of WAVEWATCH-III version 2.22, Tech. Note 222, 133 pp., Mar. Model. and Anal. Branch, Natl. Weather Serv., NOAA, Natl. Cent. for Environ. Predict., Washington, D. C.

Veron, F., W. K. Melville, and L. Lenain (2009), Measurements of ocean surface turbulence and wave-turbulence interactions, J. Phys. Oceanogr., 39, 2310-2323, doi:10.1175/2009JPO4019.1.

Wang, W., and R. X. Huang (2004), Wind energy input to the surface waves, J. Phys. Oceanogr., 34, 1276-1280, doi:10.1175/1520-0485 (2004)034<1276:WEITTS $>2.0$. CO;2.

Wen, S. C., D. C. Zhang, P. F. Guo, and B. H. Chen (1989), Parameters in wind-wave frequency spectra and their-bearing on spectrum forms and growth, Acta Oceanol. Sin., 8, 15-39.
Zhang, S. W., Y. L. Yuan, and Q. A. Zheng (2007), Modeling of the eddy viscosity by breaking waves, Acta Oceanol. Sin., 26, 116-123.

T. Ezer, Center for Coastal Physical Oceanography, Old Dominion University, Norfolk, VA 23529, USA.

C. J. Huang, F. Qiao, and Z. Song, Key Laboratory of Marine Science and Numerical Modeling, the First Institute of Oceanography, State Oceanic Administration, 6 Xianxialing Rd., Qingdao 266061, China. (qiaofl@fio.org.cn) 